\title{
Histopathological Findings in Sudden Cardiac Death: 5-years Autopsy Experience in a Tertiary Hospital in Bandung, Indonesia
}

\author{
Gian Nugraha, ${ }^{1}$ Nita Novita, ${ }^{2}$ Hermin Aminah Usman ${ }^{3}$ \\ ${ }^{1}$ Faculty of Medicine Universitas Padjadjaran, Indonesia, ${ }^{2}$ Department of Forensic and \\ Medicolegal Faculty of Medicine Universitas Padjadjaran/Dr. Hasan Sadikin General Hospital \\ Bandung, Indonesia, ${ }^{3}$ Department of Anatomical Pathology Faculty of Medicine Universitas \\ Padjadjaran/Dr. Hasan Sadikin General Hospital Bandung, Indonesia
}

\section{Abstract}

Background: Sudden death (SD) is a sudden and unexpected death with an unknown cause. However, it has been assummed that the most common causes of sudden deaths are cardiovascular or noncardiovascular causes such as gastrointestinal disease, respiratory disease, genitourinary disease, epilepsy, and trauma. This study aimed to portray histopathological findings and causes of sudden cardiac death (SCD) cases based on 5 year autopsy experience in a tertiary hospital in Bandung, Indonesia.

Methods: This study was a descriptive cross-sectional study exploring causes of SCD from 2015 to 2019 at Dr. Hasan Sadikin General Hospital, Bandung, Indonesia. All medical records with SCD and histopathology findings were retrieved from September to December 2020. Only cases with histopathological examination results were included.

Results: SCD was found in 7 of 16 patients with sudden death. Coronary atherosclerosis was the most common $(n=4)$, followed by myocardial infarction $(n=2)$ and ruptured aortic aneurysm $(n=1)$. Myocarditis and calcific aortic valve diseases were not found.

Conclusions: In this study, the most common cause of SCD is coronary atherosclerosis, which is identified mainly in older and male patients.

Keywords: Autopsy, forensic, coronary atherosclerosis, sudden cardiac death

\section{Introduction}

Death is the cessation of biological functions that maintain one's life, occurred naturally by aging or pathological event, or unnatural by third parties such as criminal conduct, selfmurder, homicide, or traffic accident. If the cause of death is undetermined and suspicion of violence has been found, unnatural death should be considered before a natural death is concluded and affirmed by a medico legal examination that is autopsy. Likewise, in sudden death, further examination is requisite to establish the cause of death. ${ }^{1,2}$ Sudden death (SD) is a death that occurs within 24 hours of the onset of symptoms or unexplained death. More than $50 \%$ of SD is caused by cardiovascular diseases, referred to sudden cardiac death (SCD). ${ }^{3}$ SCD is an unexpected death caused by cardiovascular diseases, with or without a history of heart diseases, witnessed within 1 hour after an acute attack in clinical status, or witnessed to be alive within 24 hours before. ${ }^{4}$

Even though SCD incidences have declined due to the advancement of ischemic heart disease management, SCD remains a significant public health issue, placed among the top contributors for premature mortality burden, and responsible for up to $50 \%$ of potential life lost from heart diseases. ${ }^{5}$ Approximately 7 million death/year is booked for SCD or equals 1-2 death/1000 people. ${ }^{6}$ Incidence of SCD cases varies, from 41.8/100.000 individuals in China to $99.4 / 100.000$ individuals annually in Australia and NewZealand and 50-100/100.00 in North America and Europe. ${ }^{7}$ There is no study in general about the incidence/prevalence of SCD in Indonesia, neither in Dr. Hasan Sadikin General Hospital, Bandung. SCD can be

Correspondence: Gian Nugraha, Faculty of Medicine Universitas Padjadjaran, Jalan Raya Bandung Sumedang Km. 21 Jatinangor, Sumedang Indonesia, Email: giannugraha9@gmail.com 
identified by understanding the pathogenesis process of the disease through autopsy. It is classified into coronary atherosclerosis, myocardial infarction (MI), myocarditis, aortic valve disease, and ruptured aortic aneurysm. ${ }^{2}$ In autopsy, macroscopic and microscopic findings are requisite in establishing the cause of death. ${ }^{8}$

Due to the high number of cardiovascular diseases, cardiovascular deaths, and SCD cases worldwide our study aimed to give a portrait of the causes in SCD cases and the histopathological findings based on 5 year autopsy experience in a tertiary hospital in Bandung, Indonesia.

\section{Methods}

This study was conducted from September to December 2020 with descriptive crosssectional research. Medical records of a diagnosed patient with SCD from 2015 to 2019 were collected as the data source. The Research Ethics Committee of Universitas Padjadjaran had approved data collection using the medical record with ethical exemption number: 746/UN6.KEP/EC/2020 and the Research Committee of Dr. Hasan Sadikin General Hospital. The total sampling method was used in this study.

Medical records were evaluated, included the causes of SCD with the histopathology findings of the heart, gender, and age. Data were considered eligible if the patient was diagnosed with SCD by autopsy and were histopathologically examined in the Forensic Installation, Dr. Hasan Sadikin General Hospital. Data were excluded when an autopsy procedure was not performed, no histopathology examination, and if the cardiovascular system did not cause the SD.

Data were then grouped according to the cause of SCD with its histopathology findings of the heart as followed; coronary atherosclerosis, myocardial infarction, myocarditis, calcific aortic valve disease, and ruptured aortic aneurysm. In this study, the age variable was obtained from the estimated age during the autopsy procedure and then grouped into elderly $(\geq 60)$, late adults (46$59)$, early adults $(26-45)$, and younger $(\leq 25)$.

The data were then analyzed and presented descriptively in frequency tables (Microsoft Office Excel 2016) and narrated to portrait SCD

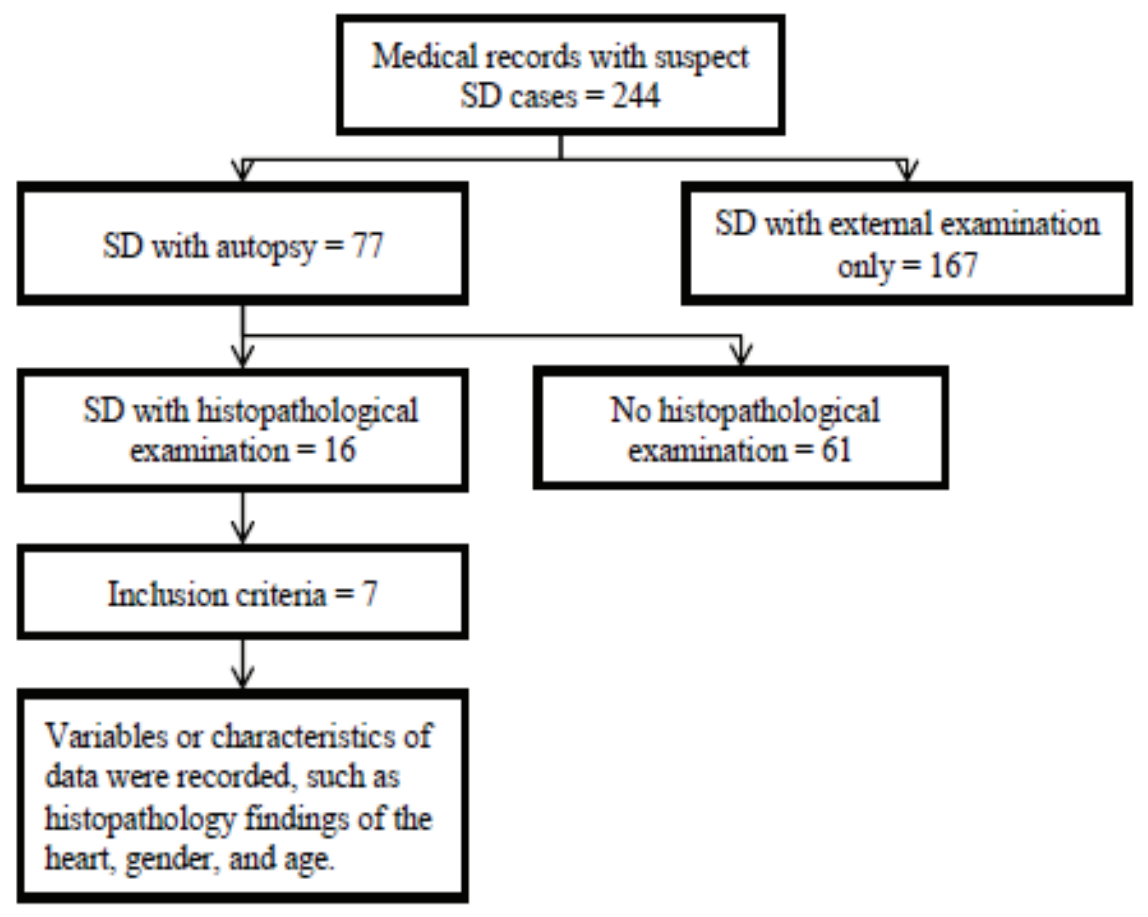

Figure 1 Flow Chart of Data Collection of Sudden Cardiac Death 2015-2019

Note: SD= sudden death. Inclusion criteria are SCD, sudden cardiac death 
Table 1 Characteristics of SCD

\begin{tabular}{lc}
\hline \multicolumn{1}{c}{ Data Characteristics } & $\begin{array}{c}\text { Frequency } \\
(\mathbf{n = 7})\end{array}$ \\
\hline Age group & - \\
Younger $(\leq 25$ years old $)$ & - \\
Early Adult $(26-45$ years old $)$ & 2 \\
Late Adult $(46-59$ years old $)$ & 5 \\
Elderly $(\geq 60$ years old $)$ & \\
Gender & 6 \\
Male & 1 \\
Female & \\
\hline
\end{tabular}

cases based on the caused and histopathology findings, age, and gender.

\section{Results}

During the 2015-2019 periods, only 16 out of 77 autopsied SD cases proceeded to histopathology examination, of which 7 were diagnosed with SCD. The most common SCD cases were in the elderly group. The youngest patient was 50 years old and the oldest was 70 years old. There was thus a trend that the incidence and the risk of SCD were increased in the older population, although due to a low number of cases, statistical analyses could not be calculated.

Based on gender, the male patient was predominantly among the cases ( 6 of 7 cases). The most common histopathology finding

Table 2 Cause of Death based on Histopathology Findings among Patient with Sudden Cardiac Disease

\begin{tabular}{lc}
\hline \multicolumn{1}{c}{ Histopathology Findings } & Frequency \\
\hline Coronary atherosclerosis & 4 \\
Myocardial infarction & \\
Atheromatous plaque & 2 \\
Platelet aggregation & - \\
Thrombus growth & - \\
Myocarditis & \\
Lymphocytic & - \\
Neutrophilic & - \\
Eosinophilic & - \\
Giant cell & - \\
Calcific aortic valve disease & - \\
Ruptured aortic aneurysm & \\
Atheromatous & 1 \\
Dissecting & - \\
\hline
\end{tabular}

of SCD was coronary atherosclerosis (4 of 7 cases) as the primary contributing factor as the cause of death whereas myocardial infarction and accompanied by atherosclerosis as the etiology was found in 2 of 7 cases. The remaining 1 case was attributed to a ruptured aortic aneurysm with an atheromatous appearance. Interestingly, there was no case found on neither myocarditis nor calcific aortic valve disease.

As for cases of coronary atherosclerosis (case 1-4), it showed a variety of appearances, such as intimal thickening, fibrous cap, ruptured plaque, and others. Nevertheless, all of them already developed the final stage of the atherosclerotic lesion, calcification, of which lumen occlusion ( 3 of 4 cases) had developed over $80 \%$. The case of myocardial infarction (case 5) implied the infarction had been going on in the first 24 hours due to the edema. The other myocardial infarction (case 6) implied infarction had been going on for 3 to 7 days and was accompanied by rupture of the heart in macroscopic findings. In the ruptured aneurysm (case 7), the aneurysm developed in the thoracic aorta, leading to massive blood loss.

\section{Discussion}

In SCD cases, especially in out-hospital settings and unwitnessed death, suspicion elements of unnatural death or involvement of third parties should be considered in the first place. Further examination is requisite to show beyond doubt that the case is linked with a medicolegal case or not, which may lead to trials and is the law of this country. Visum et Repertum (VeR), a powerful letter concluded by the doctor through comprehensive examination or autopsy holds a critical value and as legitimate evidence in the trials, which incorporate the mechanism of death, cause of death, and manner of death, also concludes whether the case is related to medicolegal cases or not. Therefore, autopsy serves as a procedure to ascertain the cause of death, issuing death certificates, and conclude medicolegal cases. ${ }^{1}$

In the advancement of technology, medicolegal autopsies procedure, specifically in SCD cases, do not only serve as tools to ascertain the cause of death but also serve as knowledge for preventing SCD by knowing underlying cardiac disorder, which can be hereditary, through integrating genetic testing in the management of SCD. Information about the risk of evolving disease in the family might of beneficial thus prevention can immediately 

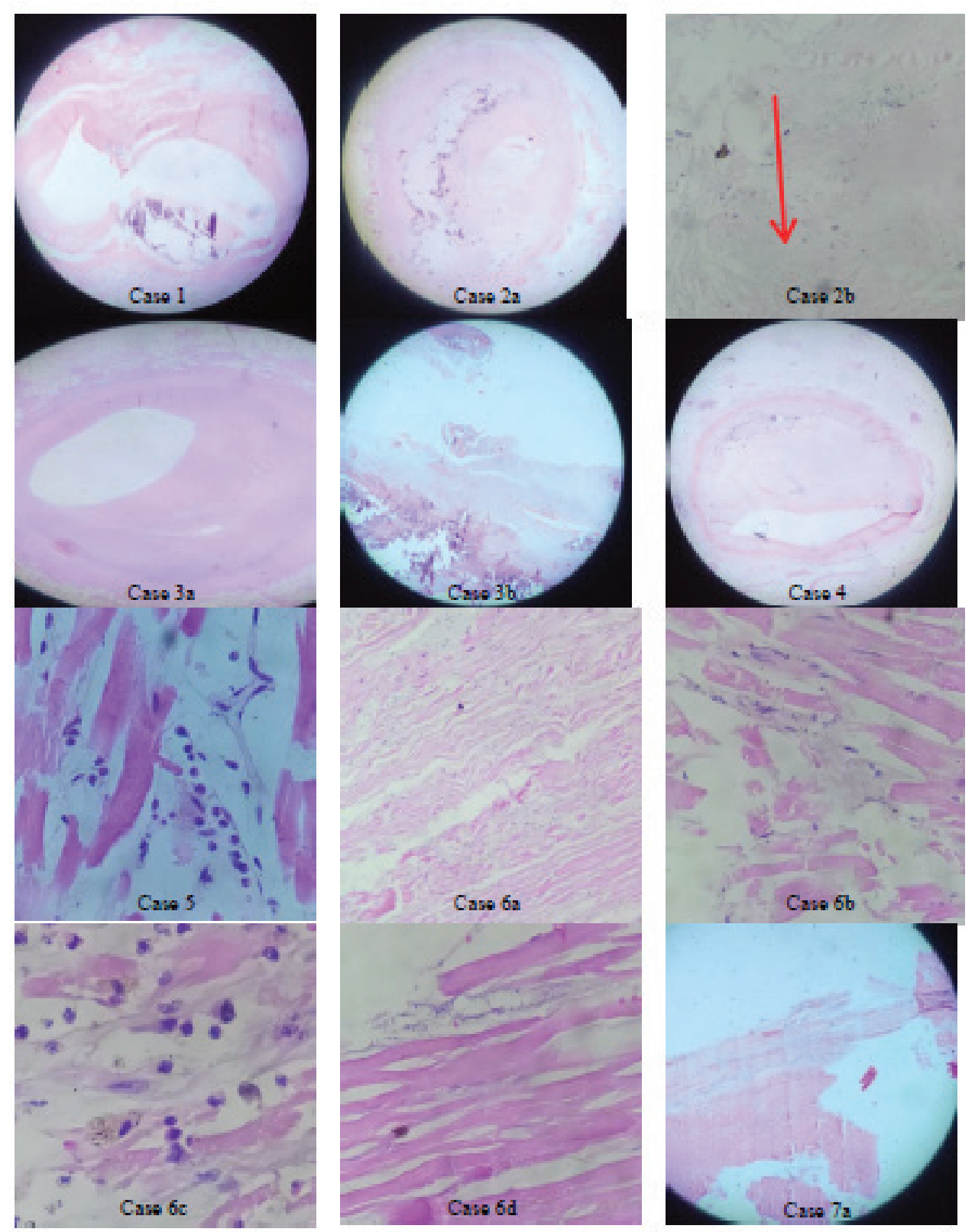

Figure 2 Histopathological with Hematoxylin and Eosin (H\&E) Stain Findings of 7 SCD Cases

Note: Case $1-4$, coronary atherosclerosis. 1 . Lumen occlusion $<80 \%$, intimal thickening, plaque ulceration, and calcification. 2 a. Lumen occlusion $>80 \%$, intimal thickening, and calcification. $2 \mathrm{~b}$. 100x magnifications, arrow indicated cholesterol crystal plaque. 3a. Lumen occlusion $>80 \%$, intimal thickening, and fibrous cap. $3 \mathrm{~b}$. Ruptured plaque and calcification. 4 . Lumen occlusion $>80 \%$, intimal thickening, and calcification. Case 5-6, Myocardial infarction. 5. Fragmentation of fiber, inflammatory cell infiltration, and edema. 6a. The waviness of fiber. $6 \mathrm{~b}$. Fragmentation of fiber. $6 \mathrm{c}$. Inflammatory cell infiltration. $6 \mathrm{~d}$. Contraction band and necrosis. 7. Ruptured aortic aneurysm with wall thinning, hyalinization of tunica media, adventitia with inflammation cell, and ruptured lumen with clotting

be carried out. ${ }^{9}$

In this study, the most common cause of death of SD cases is cardiac compared to all SD cases. Although the number of the cases is limited, another study has shown that up to $85 \%$ of SD cases are of cardiac origin. ${ }^{10}$ This limited number might be due to financial elements, ethical consideration, community knowledge of autopsy, and religion, that may contribute to the low number of autopsies in 
Indonesia and worldwide. ${ }^{11}$

Only 16 out of 77 (20.7\%) of autopsied cases in our study have been proceeded to histopathology examination since the procedure is not conducted as compulsory. The Association of European Cardiovascular Pathology Guidelines for autopsy investigation of SCD suggests that histopathological examination is one of the minimum standards procedure. ${ }^{12}$ In fact, histopathological examination holds an essential function to confirm, establish, or reject macroscopical examination..$^{13}$ This study has shown that the mechanism of death of $40 \%$ out of 428 autopsy cases has been found by microscopic examination, even though no abnormality has been shown in the macroscopic examination. In practice, extensive autopsy (including histopathology and lab examination) can suppress the unexplained cause of death from $5-10 \%$ to $1-5 \%{ }^{10}$ In other countries, such as Denmark, forensic autopsies are compulsory when external examination cannot establish the cause of death or related to the criminal investigation, and the histopathology examination is conducted as a routine examination. ${ }^{14}$ Those statements should serve as a role model for Indonesia to fulfill the primary standard in performing the autopsy, to reveal and to establish the cause of death, as well as to publish the death certificate. A similar study in Manado, Indonesia, ${ }^{15}$ has also shown a low incidence of SCD due to low cases proceeded to autopsy to establish the cause of death.

Furthermore, our study has shown that the most common cause of SCD cases is coronary atherosclerosis. About 70 to $80 \%$ causes of death in SCD cases general population is coronary heart disease (CHD) ${ }^{7,10}$ Those findings are related and may cause many risk factors for SCD parallel with a risk factor for CHD itself. ${ }^{16}$

Coronary atherosclerosis is correlated with myocardial infarction due to depletion of oxygen from anatomical alteration. Pathologists conclude that at least 80\% lumen occlusion is needed for infarction to develop. However, this number is still debatable; it turns out a relatively small degree of coronary atheroma still can cause infarction. ${ }^{2}$ Infarction in our 4 coronary atherosclerosis findings is absent in this study. These findings could occur when sampling errors are not carried out at the center of the lesion. MI can be focal, diffuse, and patchy, and it needs hours to develop due to microscopical changes in ischemic circumstances. ${ }^{14}$ Other studies conclude that
SCD in coronary atherosclerotic settings could result from myocardial electrical instability from coronary disease structural impairment or acute ischemia. ${ }^{16}$

In this study, all coronary atherosclerotic findings are accompanied by calcification lesions. Calcification is responsible for plaque progression and increased lumen occlusion that worsening and provokes cardiovascular disease (CVDs) episodes, leading to death. However, based on previous research, consuming statins would control and prevent the diseases' severity by decreasing plaque formation and stabilization of plaque. This indicates that all of the luminal narrowing and calcification cases in this study may be caused by an uncontrolled and untreated disease that provoke cardiovascular disease (CVDs) episodes and causing death. ${ }^{17}$

Interestingly, all of the MI cases in our study are caused by the atherosclerotic lesion, causing hypoperfusion and myocyte death, conform to the theory that the most common cause of myocardial infarction death is an atherosclerotic plaque and only $10 \%$ of transmural MI coronary atherosclerosis finding. Platelet aggregation and thrombus might thus the cause of this infarction. Furthermore, the duration and severity of blood flow reduction are the essential factors in disease outcome. ${ }^{18}$ MI could cause SCD from disturbing cardiac contractility, electrical stimulation of heart or arrhythmia, myocardial fibrosis, cardiac aneurysms, and rupture of the heart. $^{2}$

Rupture of an aneurysm is the most frequent extracardiac etiology of the SCD, categorized as atheromatous type and dissecting type; of which atheromatous type is the most common type; similar to our finding, which is mainly in the abdominal aorta. Although our case is in the thoracic part; this may be due to a low number of samples included. The blood would penetrate the degenerated vessels' weakest point, leaked to the surrounding tissue, and causing death. ${ }^{2}$

The incidence of SCD occurs mainly in the elderly population. ${ }^{7}$ There is a correlation between increased risk of SCD around age 35 years with increased CHD prevalence. ${ }^{19}$ In the young population ( $<35$ years), SCD incidences are much lower, approximately 0.01/100 populations annually, and primarily due to inherited genetic diseases. ${ }^{12}$

Based on gender, the incidence of SCD cases is more significant in males, with almost 4-7 fold in the population before 65 years old. ${ }^{19}$ In Manado $^{15}, 9$ out of 10 SCD cases are male, it is 
similar to our finding in this study. Coronary atherosclerosis, myocardial infarction, and ruptured aortic aneurysm, CVDs in general, need time to establish their pathogenesis and cause mortality. Therefore, those diseases relatively more often take place in the adult population. Tobacco, alcohol, excessive salt intake, obesity, hypertension, diabetes, physical inactivity, air pollutant, and toxic metals were responsible for developing CVDs. Hence, better policy, surveillance, research, treatment, and both primary or secondary prevention are needed to reduce the burden of these preventable diseases, especially for susceptible populations. ${ }^{4,20}$

There are some limitations to this study. Firstly, the low number of autopsy and histopathological examinations as a method to diagnose SCD affects the study's result, however, the distribution may reflect the general findings in another study. Secondly, most of the medical records show many unknown identity patients $(\mathrm{n}=125,41.9 \%)$; implying that the case is not being thoroughly examined, neither autopsy nor histopathology examination.

In conclusion, the most common cause of SCD in our study is coronary atherosclerosis, mainly in the older population and males. Since SCD is one of the highest burdens of mortality, it becomes a public health issue. Understanding histopathology findings is thus necessary to establish the cause of death, to fulfill the minimum standard of autopsy in SCD cases, and to improve the management and prevention in reducing the mortality of SCD.

\section{References}

1. Suryadi T. Penentuan sebab kematian dalam visum et repertum pada kasus kardiovaskuler. Jurnal Averrous. 2019;5(1):63-75.

2. Saukko P, Knight B. Knight's forensic pathology. $4^{\text {th }}$ Edition. Boca Raton: Taylor \& Francis; 2016.

3. Nofal HK, Abdulmohsen MF, Khamis AH. Incidence and causes of sudden death in a university hospital in Eastern Saudi Arabia. East Mediterr Health J. 2011;17(9):665-70.

4. Deo R, Albert CM. Epidemiology and genetics of sudden cardiac death. Circulation. 2012;125(4):620-37.

5. Isbister J, Semsarian C. Sudden cardiac death: an update. Intern Med J. 2019;49(7):826-33.

6. Parakh N. Sudden cardiac death. J Pract Cardiovasc Sci. 2015;1(2):113-9.
7. Wong CX, Brown A, Lau DH, Chugh SS, Albert CM, Kalman JM, et al. Epidemiology of sudden cardiac death: global and regional perspectives. Heart Lung Circ. 2019;28(1):6-14.

8. Suryadi T. Kematian mendadak kardiovaskuler. Jurnal Kedokteran Syiah Kuala. 2017;17(2):112-8.

9. Fellmann F, van El CG, Charron P, Michaud K, Howard HC, Boers SN, et al. European recommendations integrating genetic testing into multidisciplinary management of sudden cardiac death. Eur J Hum Genet. 2019;27(12):1763-73.

10. Campuzano O, Allegue C, Partemi S, Iglesias A, Oliva A, Brugada R. Negative autopsy and sudden cardiac death. Int J Legal Med. 2014;128(4):599-606.

11. Henky H, Que A, Yulianti K, Rutyadi D, Alit IBP. Penurunan angka autopsi di RSUP Sanglah selama delapan tahun terakhir. Jurnal Forensik dan Medikolegal Indonesia. 2019;1(2):50-5.

12. Basso C, Aguilera B, Banner J, Cohle S, d'Amati G, de Gouveia RH, et al. Guidelines for autopsy investigation of sudden cardiac death: 2017 update from the Association for European Cardiovascular Pathology. Virchows Arch. 2017;471(6):691-705.

13. de la Grandmaison GL, Charlier P, Durigon M. Usefulness of systematic histological examination in routine forensic autopsy. J Forensic Sci. 2010;55(1):85-8.

14. Yazdanfard PD, Christensen AH, TfeltHansen J, Bundgaard H, Winkel BG. Non-diagnostic autopsy findings in sudden unexplained death victims. BMC Cardiovasc Disord. 2020;20:58.

15. Rorora JD, Tomuka D, Siwu J. Temuan otopsi pada kematian mendadak akibat penyakit jantung di BLU RSU Prof. Dr. R. D. Kandou Manado periode 2007-2011. Jurnal e-Clinic. 2014;2(3):6037.

16. Sara JD, Eleid MF, Gulati R, Holmes DR. Sudden cardiac death from the perspective of coronary artery disease. Mayo Clin Proc. 2014;89(12):1685-98.

17. Jinnouchi H, Sato Y, Sakamoto A, Cornelissen A, Mori M, Kawakami R, et al. Calcium deposition within coronary atherosclerotic lesion: implications for plaque stability. Atherosclerosis. 2020;306:85-95.

18. Ghafoor M, Kamal M, Nadeem U, Husain AN. Educational case: myocardial infarction: histopathology and timing of changes. Acad Pathol. 2020;7:2374289520976639.

19. Jazayeri MA, Emert MP. Sudden cardiac 
death: who is at risk? Med Clin North Am. 2019;103(5):913-30.

20. Tzoulaki I, Elliott P, Kontis V, Ezzati M. Worldwide exposures to cardiovascular risk factors and associated health effects: current knowledge and data gaps. Circulation. 2016;133(23):2314-33. 